\title{
Criticar para construir alternativas: Isabel Ferin fala a Jorge Kanehide Ijuim
}

Foto: acervo pessoal

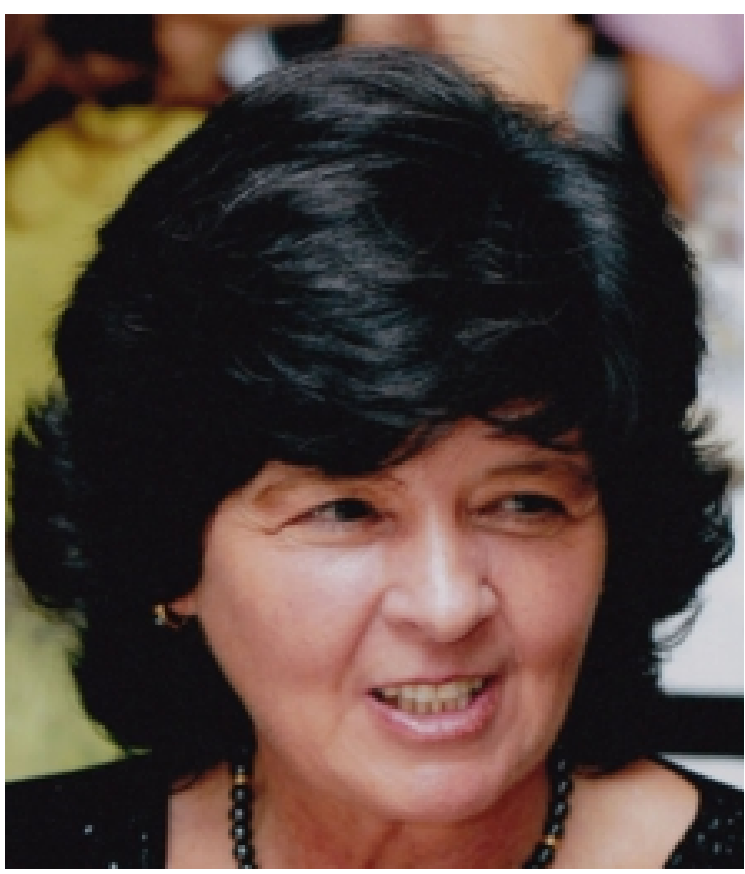

Isabel Maria Ribeiro Ferin Cunha é uma personagem conhecida no cenário da pesquisa em Jornalismo no Brasil e em Portugal. Licenciada em História pela Universidade Clássica de Lisboa (1974), tornou-se mestre e doutora pela Escola de Comunicações e Artes (ECA), da Universidade de São Paulo (1984 e 1988). Seu pós-doutoramento foi realizado no Centre Nacional de Recherche Scientifique, em Paris (1991). Há mais de 30 anos na docência e na pesquisa, desde 2006 é professora associada [no Brasil equivalente à livredocência] do Instituto de Estudos

Jornalísticos da Universidade de Coimbra.

A trajetória de Isabel Ferin é marcada por seus exaustivos e detidos trabalhos no campo de Crítica de Mídia, sempre tratando do diálogo entre a cultura portuguesa e as outras culturas - interculturalidade. Para a pesquisadora, "a análise dos media é um exercício teórico-empírico que tem como objetivo desenvolver uma consciência cívica profissional e competências de explicitação de conteúdos, com vista a construir alternativas". Além do forte traço de seus esforços na área de Mídia e Migrações, a investigadora lançou seu olhar sobre a Ficção Televisiva, uma vez que considera um produto cultural de alta relevância para a compreensão de identidades. A terceira frente de estudos, inevitavelmente, abarca as Metodologias da Comunicação, um background que proporciona acurácia e segurança a suas observações. Coordenou pesquisas 
relevantes e de interesse ao Alto Comissariado para a Imigração e Minorias Étnicas, como Media, Imigração e Minorias Étnicas, em três oportunidades, e o projeto Observatório Europeu contra as acções de discriminação étnica e de sexo.É autora de Comunicação e Culturas do Quotidiano (2002) e Jornalismo e Democracia (2007). No Brasil, além de integrar conselhos editoriais de revistas científicas, publicou Identidade e reconhecimento nos media(Revista Matrizes, 2007). [Veja mais obras de sua autoria ao final desta entrevista].

Durante o X Congresso da Lusocom - Comunicação, Cultura e Desenvolvimento, no final de setembro, em Lisboa, Isabel Ferin concedeu esta entrevista ao professor Jorge Kanehide Ijuim ${ }^{i}$ para a revista Estudos de Jornalismo e Mídia (EJM):

Após 20 anos fora de sua terra, como reencontrou Portugal? Qual era o panorama do país e em especial da imprensa?

Quando retornei, em 1992, depois da experiência de 20 anos entre Brasil e África, me senti uma imigrante, uma estranha, eu era a professora brasileira. Sou casada com um brasileiro e meus dois filhos nasceram em São Paulo. Por isso, meus filhos também eram tratados como brasileiros. Dentro da própria família éramos diferentes. Isso me causou grandes inquietações.

\section{E isso a inspirou a observar o comportamento da imprensa diante das questões da} imigração?

Passei a verificar a estrutura da notícia sobre os imigrantes em Portugal. Observei na imprensa portuguesa como os imigrantes portugueses de origem africana eram tratados. A mídia os sublinhava sempre como os africanos, pretos, jovens negros da periferia, como os causadores de todos os problemas do país. Até 1998, é importante lembrar, a imigração fundamentalmente era de pessoas de países de origem africana de língua portuguesa, como Guiné-Bissau, Cabo Verde, Angola. Com uma série de obras monumentais no país, começaram a chegar os chamados imigrantes do Leste e os brasileiros. Até então, quem vinha do Brasil eram maioritariamente pessoas qualificadas - dentistas, professores, informáticos, publicitários - e entraram em escalões sociais altos. Quando chegaram as mulheres para serem empregadas domésticas ou para o comércio e os homens para a construção civil, começaram a aparecer na imprensa as imagens da imigração. Do Leste, eram sempre associados a organizações mafiosas, 
criminosas. As mulheres brasileiras eram relacionadas à prostituição, os homens ao banditismo. Ganhavam matérias de primeira página, pois pela primeira vez a imigração era matéria-prima de alto valor, estimuladora de pânico moral para aumentar audiências. O tratamento era com estereótipos, com um tom superior de colonizador pedante.

Foi um momento de boom português, pois os fundos estruturais europeus despejaram muito dinheiro no país. A construção civil cresceu e os trabalhadores foram atraídos pelas grandes obras. Os imigrantes eram uma classe desprotegida, explorada pelas grandes construtoras - empresas protegidas pelo Estado Português. Mas as pessoas se organizaram, com apoio de entidades sociais, da Igreja católica, não foi por acaso que o primeiro Alto Comissário para a Imigração e Minorias Étnicas veio a ser um religioso jesuíta. Estes fizeram intensas pressões às empresas jornalísticas que foram obrigadas a rever seu comportamento.

\section{Tais fatos coincidem com as mudanças na mídia nos anos 1990...}

$\mathrm{Na}$ época houve uma projeção cultural. Aconteceu uma transformação no cenário da comunicação portuguesa com o surgimento das emissoras de TV privadas. A nova cultura fez sucumbir a profissão do jornalismo; alterou-se o princípio de serviço público, que estava muito acomodado, sem concorrência. E a imigração se tornou matéria-prima para essa concorrência por audiência. Isso também tem um componente cultural, porque nós fomos colonizadores, há a cultura do colonizador sobre $\mathrm{o}$ colonizado, carregada de estereótipos sobre aqueles que colonizamos. O estereótipo da mulata, por exemplo, que poderia ser angolana, cabo-verdiana ou brasileira. Com a exibição das novelas brasileiras em Portugal, este estereótipo colonial foi revificado a partir da exibição da telenovela Gabriela, em 1977, para o bem e para o mal.

\section{Daí sua atenção à ficção televisiva? Qual sua importância neste contexto?}

Posso dizer que hoje em dia a afinidade que a população portuguesa tem com os brasileiros, com o português que se fala no Brasil, é algo inédito, porque nem os ingleses, nem os franceses têm essa afinidade com as ex-colônias, na questão do idioma, do vocabulário, como nós temos com o Brasil, e isso se deve às telenovelas. Por um lado, eleva a identidade entre portugueses e brasileiros, por outro reforça estereótipos. Essa imagem dos imigrantes de origem africana - muitos deles portugueses que não nasceram em Portugal - era estigmatizada pela mídia como "africanos". Os brasileiros surgem com os estigmas de homens malandros e mulheres prostitutas, também 
projetados pelas telenovelas. O caso das "Mulheres de Bragança" foi emblemático: com a presença de brasileiras atuando na prostituição, as mulheres casadas daquela cidade se mobilizaram e apresentaram queixas ao Bispo, à Câmara, invocando toda argumentação sobre Gabriela, Tieta, Jorge Amado. Protestaram contra as brasileiras que "levavam seus maridos". A partir de uma "curiosidade", este caso teve repercussão internacional através da revista Times, que ganhou uma dimensão exagerada, porque nenhuma publicação dá a mesma atenção, por exemplo, à questão da prostituição em Londres ou em Paris.

Em sua opinião, quais as principais virtudes e quais são suas principais críticas à imprensa portuguesa?

A imprensa portuguesa atual é master voice - a voz do dono -, há muitas características de voz do dono e muito pouco de uma imprensa interventiva, de denúncia, de cidadania. Há razões muito concretas, como a de todos os órgãos de comunicação estar nas mãos de grandes grupos - que eventualmente têm a mídia, mas também estão ligados a petróleo, a bancos ou outros negócios. Outro fator é o peso que esses órgãos de comunicação têm na cumplicidade com o Estado, que é um dos grandes financiadores da imprensa, por meio da publicidade. Aliás, este é um trabalho [de investigação] a fazer, o de perceber até que ponto o Estado manipula essa publicidade para manter uma "boa imprensa", seja em que governo for. Já houve muitas denúncias, mas sempre acabam ficando em "águas de bacalhau”, como nós dizemos [termina em pizza]. Ainda sem dados empíricos, posso citar sobre as medidas de austeridade diante da situação econômica, por exemplo. Até há três semanas, os órgãos de imprensa, num discurso de mastervoice, eram unânimes em dizer que não havia outra alternativa. Este discurso fragmentou-se agora, inclusive o tom dos pivôs, os formadores de opinião, que era um tom neutro, já se fragmentou. Porque já não há um consenso entre os grandes grupos empresariais com relação à disfunção desta situação. [O primeiro-ministro Passos Coelho anunciou novas medidas de austeridade em 7 de setembro, o que causou a insatisfação generalizada no país].

\section{Agora num sentido mais amplo, como está o jornalismo português em termos técnicos?}

Tecnicamente o jornalismo português tem o nível do europeu e até do norte-americano. Meus colegas jornalistas mais antigos dizem que nosso jornalismo perdeu as 
características do jornalismo europeu e está mais próximo do infotenimento norteamericano. Mas, do ponto de vista técnico é bom, em manobras técnicas, distribuição, formatação.

Os jornalistas mais experientes, antigos, quando dizem que o jornalismo português perdeu um pouco das características europeias, querem dizer o que? O jornalismo era mais formador de opinião?

Sim, era um jornalismo tradicional que já não existe mais, um jornalismo de opinião, de pautas, de missões, muito fundado na opinião do jornalista e não das equipes. O jornal tinha a personalidade das pessoas que constituíam esta redação. Hoje não, são marcas amorfas porque não se sabe quem está lá. Se conhece os líderes de opinião, que escrevem, que opinam, mas não se conhece propriamente os jornalistas que fazem as notícias. É uma equipe uniforme, anônima.

As equipes anônimas e a rotina atual, que é pressionada pelo fator tempo, fazem com que a cobertura aconteça com a velocidade exigida. Quais as características do material produzido?

São matérias sem profundidade, numa rotina, com fontes de secretária [as agências noticiosas], sem investigação, sem consultar outras fontes, sempre à espera que as fontes cheguem lá. Por isso, a maioria das fontes são anônimas ou institucionais.

Sobre os impactos das tecnologias, vivemos numa época de convergência de mídias. Isso tem interferido nos modelos jornalísticos praticados no país?

Sim, mesmo porque na maioria das redações é comum [impresso, TV, on-line...]. No online há muito do hipertexto, notícias cada vez mais curtas, menos profundas, tentando fazer links na forma do hipertexto. Nesse aspecto, o jornalismo on-line contamina o jornalismo impresso mais que o contrário. Há uma hibridez e os jornalistas de on-line dizem que ainda não se escreve para o on-line, mas na verdade os impressos também não escrevem mais como antes. Portanto, essa hibridez traz em velocidade notícias curtas, pobres, sem testemunhas, sem o contraditório.

A senhora viveu no Brasil e hoje, mesmo à distância, acompanha a imprensa brasileira. Qual sua opinião sobre o jornalismo no Brasil? 
Apesar de ter constrangimentos semelhantes aos dos portugueses - pressões políticas ou econômicas -, me parece que a imprensa brasileira tem mais um pendor pela investigação. O que em Portugal não temos, por algumas razões. Por sermos um país pequeno, é impossível se fazer denúncias, e o sistema judiciário está completamente bloqueado. Há denúncias em praça pública, mas não chegam ao ponto de escandalização, não arruínam a vida da pessoa. A pessoa passa um mau bocado, eventualmente tem culpa ou não tem, a gente não fica a saber. No Brasil, por ser um país grande, mais jovem, há uma preocupação maior com a denúncia e a investigação, sobretudo a partir dos últimos governos - de Fernando Henrique Cardoso, do Lula e agora de Dilma - vem crescendo a preocupação de atribuir as culpas ou não.

Outro aspecto é que a imprensa no Brasil pende mais ao espetacular, enquanto aqui a imprensa é mais neutra, tem enquadramento mais de substância. Essa característica da nossa imprensa traz algumas garantias, como por exemplo, a vida privada é intocável. No entanto, aqui é impossível se fazer uma investigação sobre questões como enriquecimento ilícito. A espetacularização que se faz em Portugal é mais pela fotografia, que muitas vezes está em dissonância com o texto; noto que aqui eventualmente a fotografia diz mais que o texto. 
Mais obras da autora:

Em Portugal

Comunicação e Culturas do Quotidiano, Lisboa: Quimera, 2002.

Jornalismo e Democracia, Lisboa: Paulus, 2007.

Televisão e Imagens da Diferença. Lisboa: Quimera, 2006.

Imigração, diversidade étnica, linguística, religiosa e cultural na Imprensa e na Televisão. Lisboa: ERC/OI/ACIDI, 2009.

Memórias da Telenovela: produção e recepção. Lisboa: Quimera, 2011.

Análise dos Media. Coimbra: Imprensa da Universidade de Coimbra, 2012.

\section{No Brasil}

The Portuguese Postcolonial Migration System: a qualitative approach In: COGO, D., HUERTAS, A., ELHAJJ, M. Diaspora, communication technologies and transnational identities .E.book, 2011.

Identidade e reconhecimento nos media. Revista Matrizes. São Paulo, V.1 N.1, 2007: 187-208.

Disponível em: http://www.matrizes.usp.br/index.php/matrizes/article/view/31 .

O SPSS e os estudos sobre os media e o jornalismo in LAGO, C. e BENETTI, M. Metodologia de Pesquisa em Jornalismo. Petrópolis: Vozes, 2007. 
${ }^{\text {i }}$ Professor do Departamento de Jornalismo da Universidade Federal de Santa Catarina e do Programa de Pós-Graduação em Jornalismo na mesma instituição. Atualmente em estágio pós-doutoral na Universidade de Coimbra com apoio da Capes.

Este artigo e todo o conteúdo da Estudos em Jornalismo e Mídia estão disponíveis em http://www.periodicos.ufsc.br/index.php/jornalismo/index

Estudos em Jornalismo e Mídia está sob a Licença Creative Commons. 